This is the peer reviewed version of the following article: F. Schendzielorz et al., Angew. Chem. Int. Ed., 2019, 58, 830-834, which has been published in final form at DOI: 10.1002/anie.201812125. This article may be used for non-commercial purposes in accordance with Wiley Terms and Conditions for Use of Self-Archived Versions.

\title{
Metal-Ligand Cooperative Synthesis of Benzonitrile via Electrochemical Reduction and Photolytic Splitting of Dinitrogen
}

\author{
Florian Schendzielorz, ${ }^{[a]}$ Markus Finger, ${ }^{[a]}$ Josh Abbenseth, ${ }^{[a]}$ Christian Würtele ${ }^{[a]}$ Vera Krewald, ${ }^{*[b]}$ and \\ Sven Schneider ${ }^{*[a]}$
}

Dedicated to Prof. Dr. F. Tuczek on the occasion of his $60^{\text {th }}$ birthday

\begin{abstract}
Thermal nitrogen fixation relies on strong reductants to overcome the extraordinarily large $\mathrm{N}-\mathrm{N}$ bond energy. Photochemical strategies that drive $\mathrm{N}_{2}$ fixation are scarcely developed. Here, the synthesis of a dinuclear $\mathrm{N}_{2}$-bridged complex is presented upon reduction of a rhenium(III) pincer platform. Photochemical splitting into terminal nitride complexes is triggered by visible light. Clean $\mathrm{N}$ transfer with benzoyl chloride to free benzamide and benzonitrile is enabled by cooperative $2 \mathrm{H}^{+} / 2 \mathrm{e}^{-}$transfer of the pincer ligand. A threestep cycle is demonstrated for $\mathrm{N}_{2}$ to nitrile fixation that relies on electrochemical reduction, photochemical $\mathrm{N}_{2}$-splitting and thermal $\mathrm{N}$ transfer.
\end{abstract}

The Haber-Bosch process consumes large amounts of energy, for the generation of $\mathrm{H}_{2}$. Electrocatalytic $\mathrm{N}_{2}$ reduction has therefore been targeted as an attractive alternative. ${ }^{1,2}$ Nitrogen fixation at ambient conditions with molecular catalysts has seen remarkable progress, ${ }^{3}$ in some cases also for electrochemical ammonia generation. ${ }^{4}$ The direct synthesis of other compounds than $\mathrm{NH}_{3}$ from $\mathrm{N}_{2}$ remains a formidable challenge. Catalytic protocols are only known for trisilylamine. ${ }^{5}$ Nitriles, ${ }^{6,7,8}$ isocyanates, ${ }^{9}$ silylamines, ${ }^{10,11}$ and borylamines, ${ }^{12}$ have been synthesized within stoichiometric, cyclic reaction sequences that allow for evaluating strategies to offset the extremely strong $N \equiv N$ bond $(225 \mathrm{kcal} / \mathrm{mol})$, enable $\mathrm{E}-\mathrm{N}(\mathrm{E}=\mathrm{C}, \mathrm{Si}, \mathrm{B})$ bond formation and deliver six reduction equivalents. All reported 'synthetic cycles' proceed through initial $\mathrm{N}_{2}$ cleavage into nitride complexes. Subsequent $N$-transfer typically requires strong electrophiles like alkyl triflates. The thermochemistry of $\mathrm{N}_{2}$ splitting must therefore be tuned to avoid nitride overstabilization and enable functionalization with reagents that are more compatible with reductive conditions.

We have examined $\mathrm{N}_{2}$ activation and splitting, i.e. triggered by chemical or electrochemical reduction of pincer halide complexes. ${ }^{13,14}$ The rhenium(III) precursor $\left[\operatorname{ReCl}_{2}\left(\mathrm{PNP}^{t \mathrm{Bu}}\right)\right]$ (1; $\left.\mathrm{PNP}^{\mathrm{tBu}}=\mathrm{N}\left(\mathrm{CH}_{2} \mathrm{CH}_{2} \mathrm{PtBu}_{2}\right)_{2}\right)$ exhibits a complex mechanism via rapid $\mathrm{Re}^{\mathrm{III} / \mathrm{Re}} \mathrm{e}^{\prime \prime}$-reduction, $\mathrm{N}_{2}$-binding, halide loss, $\mathrm{Re}^{\prime \prime} / \mathrm{Re}^{\prime}$ reduction and $\mathrm{Re}^{1 /} / \mathrm{Re}^{\mathrm{III}}$-comproportionation. ${ }^{13 \mathrm{~b}}$ Splitting of the

[a] M. Sc. F. Schendzielorz, Dr. Markus Finger, M. Sc. J. Abbenseth Dr. C. Würtele, Prof. Dr. S. Schneider Georg-August-Universität Institut für Anorganische Chemie Tammannstrasse 4, 37077 Göttingen (Germany)

E-mail: sven.schneider@chemie.uni-goettingen.de

[b] Dr. Vera Krewald

Department of Chemistry

University of Bath

Claverton Down, Bath BA2 7AY, United Kingdom

Supporting information for this article is given via a link at the end of the document. resulting dinuclear complex $\left[\left(\mu-\mathrm{N}_{2}\right)\left\{\operatorname{ReCl}\left(\mathrm{PNP}^{\mathrm{tBu}}\right)\right\}_{2}\right](2)$ is ratedetermining and gives the nitride complex $\left[\operatorname{ReNCl}\left(\mathrm{PNP}^{\mathrm{tBu}}\right)\right](3)$. A simple electronic structure model for the Re-N-N-Re core of key intermediate $2\left(\pi^{10} \delta^{4}\right.$-configuration; Scheme 1$)$ provides a starting point to tune the thermochemistry..$^{15}$ We now report a modified platform that splits $\mathrm{N}_{2}$ photolytically into more reactive nitrides that can be transferred with benzoyl chloride. The pincer ligand serves as $2 \mathrm{e}^{-} / 2 \mathrm{H}^{+}$reservoir, enabling electrochemical $\mathrm{N}_{2}$ reduction, photochemical splitting and thermal transfer within a three-step cycle.

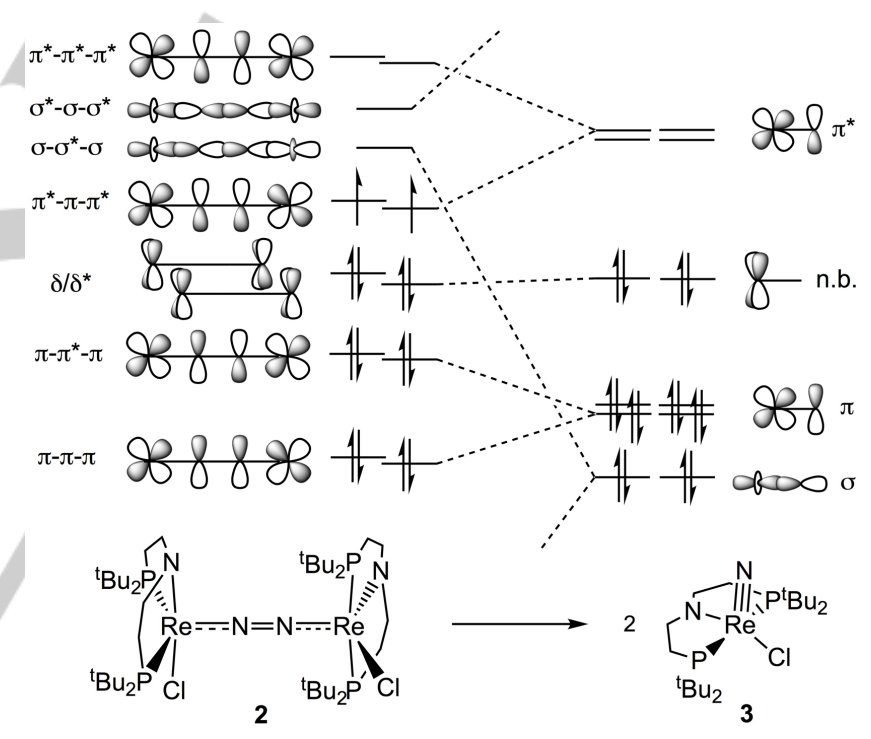

Scheme 1. Schematic frontier orbital correlation diagram for the splitting of $\mathrm{N}_{2}$ bridged complex $\mathbf{2}$ into two nitrides $\mathbf{3}$ (n.b. = non bonding). ${ }^{13 b, 15}$

The $\mathrm{Re}^{\mathrm{III}}$ complex $\left[\mathrm{ReCl}_{3}\left(H \mathrm{PNP}{ }^{\mathrm{PPr}}\right)\right]$ (4) was obtained in $70 \%$ isolated yield. ${ }^{16}$ In contrast to 1 , the amide complex $\left[\mathrm{ReCl}_{2}\left(\mathrm{PNP}^{\mathrm{iPr}}\right)\right]$ could not be isolated in analytical purity. 4 displays strongly shifted NMR resonances, as exemplified by the ${ }^{31} \mathrm{P}\left\{{ }^{1} \mathrm{H}\right\}-N M R$ signal $(\delta \mathrm{P}=-1525.9 \mathrm{ppm})$. However, the sharp signals exhibit well-resolved $J$-coupling. This observation can be rationalized with a magnetic, energetically isolated ground state that results from excited state admixture via spin-orbit coupling. Contributions from temperature independent paramagnetism (TIP) are well documented for $3^{\text {rd }}$ row complexes with $d^{4}$ (octahedral $\mathrm{Re}^{\mathrm{III},} \mathrm{O} \mathrm{s}^{\mathrm{IV}}$ ) and $\mathrm{d}^{6}$ configuration (square-planar, Os"). ${ }^{17}$ Single-crystal X-ray diffraction confirmed meridional coordination of the neutral diphosphinoamine ligand (Figure 1a). 
This is the peer reviewed version of the following article: F. Schendzielorz et al., Angew. Chem. Int. Ed., 2019, 58, 83o-834, which has been published in final form at DOI: 10.1002/anie.201812125. This article may be used for non-commercial purposes in accordance with Wiley Terms and Conditions for Use of Self-Archived Versions.

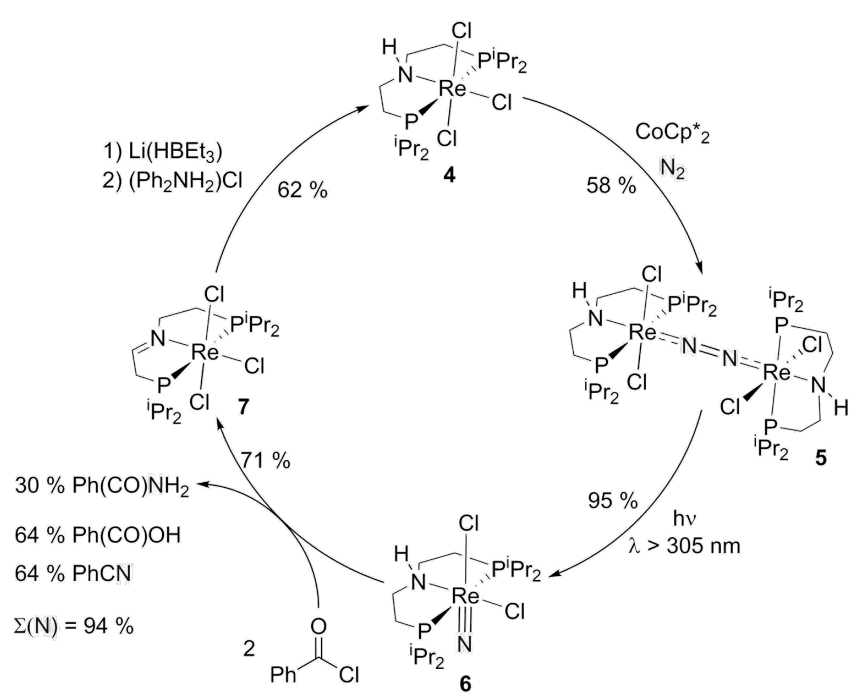

Scheme 2. Four step synthetic cycle for benzonitrile/benzamide synthesis.

Complex 4 was investigated by cyclic voltammetry (CV) under argon. Quasireversible, scan rate dependent reduction is observed at $-1.84 \mathrm{~V}$ suggesting chloride loss on the CV timescale. ${ }^{16,} 18$ Chemical reduction with 1 equiv. $\mathrm{CoCp}_{2}^{*}$ in tetrahydrofuran (THF) under an $\mathrm{N}_{2}$ atmosphere (Scheme 2) gives an intensely blue product (5) in around $60 \%$ isolated yield. Complex $\mathbf{5}$ exhibits sharp and strongly shifted NMR signals suggesting an even-electron compound with a TIP contribution. Symmetric $\mathrm{N}_{2}$ binding was confirmed by a single signal in the ${ }^{15} \mathrm{~N}\left\{{ }^{1} \mathrm{H}\right\}-\mathrm{NMR}$ spectrum and a band at $1733 \mathrm{~cm}^{-1}\left({ }^{15} \mathrm{~N}_{2}-5\right.$ : $\left.1675 \mathrm{~cm}^{-1}\right)$ in the resonance Raman spectrum. ${ }^{16}$ Two doublets in the ${ }^{31} \mathrm{P}\left\{{ }^{1} \mathrm{H}\right\}-\mathrm{NMR}$ spectrum $(\delta \mathrm{P}=-370.6 /-380.4 \mathrm{ppm})$ with mutual trans-coupling $\left({ }^{2} \mathrm{JPP}=237 \mathrm{~Hz}\right)$, eight ${ }^{1} \mathrm{H}$ NMR signals assignable to $\mathrm{CH}_{3}$-groups and one amine $\mathrm{NH}$-signal are in agreement with an $\mathrm{N}_{2}$ bridged, dinuclear compound with $\mathrm{C}_{2}$ symmetry, in analogy to 2. ${ }^{13 \mathrm{~b}}$ Structural assignment as $\left[\left(\mu-\mathrm{N}_{2}\right)\left\{\operatorname{ReCl}_{2}\left(H P N P^{\mathrm{PP}}\right)\right\}_{2}\right]$ was further substantiated by LIFDI mass spectrometry.

The molecular structure was confirmed by single crystal $X$ ray diffraction (Figure $1 \mathrm{~b}$ ). ${ }^{16}$ The asymmetric unit features two octahedrally coordinated, linearly $\mathrm{N}_{2}$-bridged Re-ions. The $\mathrm{N}-\mathrm{N}$ bond length $(1.169(5) \AA)$ is slightly shorter compared with 2 $(1.202(10) \AA),{ }^{13 b}$ indicating moderate $N_{2}$ activation in agreement with the Raman data. In contrast to 2 , the pincer nitrogen atoms are located trans to the $\mathrm{N}_{2}$ bridge. The two $\left\{\operatorname{ReCl}_{2}\left(H_{P N P^{i P r}}\right)\right\}$ fragments are twisted with respect to each other by $75.5^{\circ}$ giving rise to idealized $C_{2}$ symmetry.

Unlike 2, complex 5 shows remarkable thermal stability. No decomposition was observed over several days, even upon heating to $60^{\circ} \mathrm{C}$ in THF. Thermal splitting was therefore examined computationally. Density functional theory (DFT) nicely reproduced the geometry of $5 .{ }^{16}$ In analogy to $2,{ }^{13 b}$ an electronic triplet configuration was obtained as the ground state. While any spin-orbit coupling effects likely present in this dimer are insufficiently described by DFT, the high kinetic barrier $\left(\Delta G^{\ddagger}{ }_{298}=\right.$ $41.8 \mathrm{kcal} \mathrm{mol}^{-1}$ ) computed for thermal cleavage of 5 into the transdichloro nitride $\left[\operatorname{Re}(\mathrm{N})\left(\right.\right.$ trans- $\left.\left.\mathrm{Cl}_{2}\right)\left(\mathrm{HPNP}^{\mathrm{IPr}}\right)\right] \quad\left(6^{\text {trans }}\right)$ is in accordance with experiment and contrasts with cleavage of 2

$\left(\Delta G^{\ddagger}{ }_{298}=26.9 \mathrm{kcal} \mathrm{mol}^{-1}\right){ }^{13 \mathrm{~b}}$ Interestingly, splitting of $\mathbf{5}$ into $\mathbf{6}^{\text {trans }}$ is almost thermoneutral $\left(\Delta G^{\circ} 298=2.2 \mathrm{kcal} \mathrm{mol}^{-1}\right)$, as compared with strongly exergonic splitting of $\mathbf{2}$ into square-pyramidal $\mathbf{3}$ $\left.\left(\Delta G^{\circ}{ }_{298}=-40.3 \mathrm{kcal} \mathrm{mol}^{-1}\right)\right)^{13 \mathrm{~b}}$ The less favorable thermochemistry for six-coordinate $6^{\text {trans }}$ is attributed to the nitride trans-influence as expressed by a long Re-NPNP bond ( $2.53 \AA$ ) and distorted pincer binding. Accordingly, relaxation to isomeric $\left[\operatorname{Re}(\mathrm{N})\left({ }\right.\right.$ is- $\left.\left.-\mathrm{Cl}_{2}\right)\left(H \mathrm{PNP} \mathrm{P}^{\mathrm{iPr}}\right)\right] \quad(6)$ is strongly favorable $\left(\Delta \mathrm{G}^{\circ}{ }_{298}\right.$ $=-11.0 \mathrm{kcal} \mathrm{mol}^{-1}$ per molecule).

The striking thermal stability of $\mathbf{5}$ vs. 2 can be rationalized by qualitative molecular orbital (MO) considerations. Thermal cleavage of a linearly $\mathrm{N}_{2}$ bridged $\mathrm{M}_{2} \mathrm{~N}_{2}$ core proceeds via electron transfer into an $\mathrm{MO}$ with $\mathrm{M}-\mathrm{N}-\mathrm{N}-\mathrm{M} \sigma-\sigma *-\sigma-c h a r a c t e r(S c h e m e ~ 1)$ within a zig-zag shaped transition state (TS). ${ }^{15,13 b, 19}$ Ligands trans to the $\mathrm{N}_{2}$-bridge raise this $\mathrm{MO}$ in energy, thereby disfavoring $\mathrm{N}_{2}$ splitting. A classic case for such geometry controlled reactivity might be the trisanilides $\left[(\operatorname{RArN})_{3} \mathrm{Mo}_{2}\left(\mathrm{~N}_{2}\right)\right],{ }^{20}$ which split into nitrides in contrast to analogous triamidoamine complexes. ${ }^{3 a}$

a)

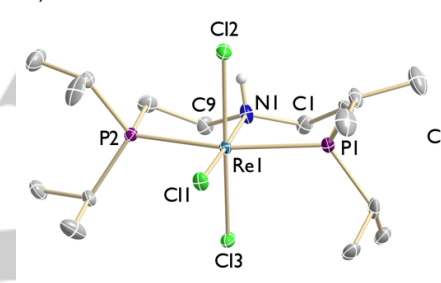

c)

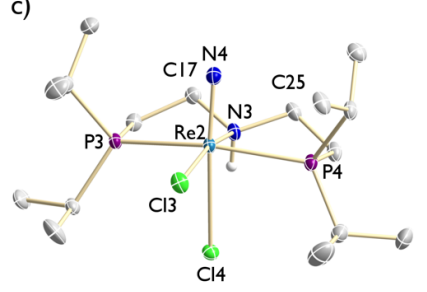

Figure 1. Molecular structures of 4 (a), 5 (b), 6 (c) and 7 (d) in the crystal obtained by single crystal $\mathrm{X}$-ray diffraction. Hydrogen atoms were omitted for clarity except $\mathrm{NH}$ protons. ${ }^{16}$

To overcome kinetically hindered $\mathrm{N}_{2}$-splitting we sought to populate $\mathrm{N}-\mathrm{N}$ antibonding $\mathrm{MOs}$ by electronic excitation. ${ }^{9,21,22}$ Photolysis of 5 in THF with a Xe arc lamp $(\lambda>305 \mathrm{~nm})$ led to gradual color change to yellow over $2 \mathrm{~h} .{ }^{31} \mathrm{P}$ and ${ }^{1} \mathrm{H}$ NMR spectra revealed the formation of cis-dichloro nitride complex 6 (Scheme 2 ) in $95 \%$ spectroscopic yield upon comparison with an original sample. ${ }^{16}$ Use of ${ }^{15} \mathrm{~N}_{2}$-labelled 5 confirmed photolytic splitting of the $\mathrm{N}_{2}$ ligand by ${ }^{15} \mathrm{~N}\left\{{ }^{1} \mathrm{H}\right\}$ NMR spectroscopy. A quantum yield below $1 \%$ was estimated by actinometry. ${ }^{16}$ The configuration of 6 requires isomerization before or after $\mathrm{N}_{2}$-splitting. Photolysis was therefore carried out in the presence of $\mathrm{NHex}_{4} \mathrm{Cl}(0-500$ equiv.). ${ }^{16}$ The independence of the reaction rate excludes isomerization by chloride (photo)dissociation prior to or as the rate determining step. 
This is the peer reviewed version of the following article: F. Schendzielorz et al., Angew. Chem. Int. Ed., 2019, 58, 83o-834, which has been published in final form at DOI: 10.1002/anie.201812125. This article may be used for non-commercial purposes in accordance with Wiley Terms and Conditions for Use of Self-Archived Versions.
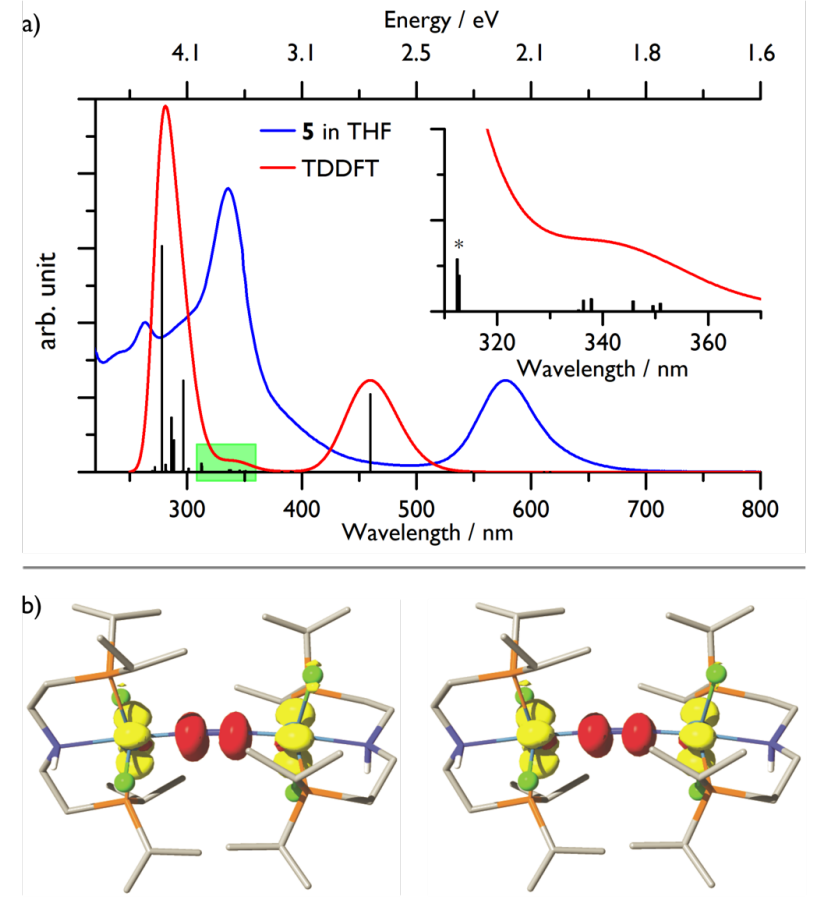

Figure 2. a) Comparison of the experimental (blue) and TDDFT-computed (red; $S=1$; see ESI for details) electronic absorption spectra. The productive region for $\mathrm{N}_{2}$ splitting is highlighted in the computed spectrum (green) and shown in the inset. b) Difference densities (loss in yellow, gain in red) of the two transitions marked with an asterisk in the inset.

Complex 5 exhibits two maxima above $300 \mathrm{~nm}$ in the UVvis spectrum $\left(\lambda_{\max }=336, \varepsilon=38027 \mathrm{M}^{-1} \mathrm{~cm}^{-1} ; 578 \mathrm{~nm}, \varepsilon=12294\right.$ $\mathrm{M}^{-1} \mathrm{~cm}^{-1}$; Figure 2a). Wavelength selective photolysis indicates that the productive excitations for $\mathrm{N}_{2}$-splitting are centered at a shoulder around $400 \mathrm{~nm}$ allowing for the use of a violet LED $(390 \mathrm{~nm})$ with the same yield. ${ }^{16}$ TD-DFT reasonably well reproduced the electronic absorption spectrum (Figure 2a) with almost identical results for the open-shell singlet and triplet electronic structure configurations. ${ }^{16}$ Computational evaluation of the highest intensity, yet unproductive absorptions indicates dominant contributions from transitions within the Re-N-N-Re $\pi$ manifold, such as $\left(\pi^{*}-\pi-\pi^{*}\right) \rightarrow\left(\pi^{*}-\pi^{*}-\pi^{*}\right)$ (calc: $278 \mathrm{~nm}, 4.46 \mathrm{eV}$ ) and $\left(\pi-\pi^{*}-\pi\right) \rightarrow\left(\pi^{*}-\pi-\pi^{*}\right)$ (calc: $\left.460 \mathrm{~nm}, 2.70 \mathrm{eV}\right)$. In contrast, two transitions in the productive spectral region (Figure $2 \mathrm{a}$, inset) exhibit mainly $\left(\delta / \delta^{*}\right) \rightarrow\left(\pi^{*}-\pi^{*}-\pi^{*}\right)$ character (Figure $2 \mathrm{~b}$ ), implying considerably stronger $\mathrm{Re} \rightarrow \mathrm{N}_{2}$ charge transfer. The weak oscillator strengths $\left(f_{\text {osc }} \leq 0.02\right)$ are in line with the low quantum yield obtained for photolytic splitting of the $\mathrm{N}_{2}$ bridge.

While the excited state dynamics are not known at this point, the $\mathrm{Re} \rightarrow \mathrm{N}_{2}$ MLCT character of these states is consistent with $\mathrm{N}_{2}$ cleavage. Occupation of $\mathrm{Re}-\mathrm{N}-\mathrm{N}-\mathrm{Re}\left(\pi^{*}-\pi^{*}-\pi^{*}\right)$-MOs weakens $\mathrm{N}-\mathrm{N} \pi$-bonding and increases the flexibility of the $\mathrm{Re}_{2} \mathrm{~N}_{2}$-core, which could facilitate cleavage via a zig-zag TS. At the same time, charge separation should enhance $\mathrm{Re}-\mathrm{N}$ bonding. The spectral features of 5 resemble the visible region of $\left[\left\{C p^{*}(\text { depf }) M o\right\}_{2}\left(\eta_{1}: \eta_{1}: \mu^{2}-N_{2}\right)\right] \quad\left(\right.$ depf $\quad$ = 1, $1^{\prime}-$ bisdi(ethylphosphino)ferrocene), which also splits into nitrides upon photolysis at $580>\lambda>400 \mathrm{~nm}^{22 \mathrm{~d}}$
In the solid state (Figure 1c), ${ }^{16} \mathbf{6}$ retains octahedral coordination with one significantly elongated $\mathrm{Re}-\mathrm{Cl}$ bond (2.4309(7) $\AA$ vs. 2.6712(7) $\AA$ ), reflecting the nitride trans-influence. In turn, the $\operatorname{Re} \equiv \mathrm{N}$ bond $(1.669(2) \AA)$ is longer compared to fivecoordinate $\left.\left[\operatorname{Re}(\mathrm{N}) \mathrm{Cl}\left(\mathrm{HPNP}^{\mathrm{tBu}}\right)\right] \mathrm{Cl} \quad(1.642(4) \AA)\right)^{13 \mathrm{a}}$ Addition of $\mathrm{NaBAr}_{24}\left(\mathrm{BArF}_{24}=\right.$ tetrakis-(3,5-(trifluoromethyl)phenyl)borate) to 6 in THF results in two new ${ }^{31} \mathrm{P}$ NMR signals that are assigned to two isomers of $\left[\operatorname{Re}(\mathrm{N}) \mathrm{Cl}\left(\mathrm{HPNP}^{\mathrm{PPr}}\right)\right]^{+}{ }^{+16}$ In turn, 6 is fully restored upon addition of $\mathrm{NHex}_{4} \mathrm{Cl}$. Hence, six-coordinate $\left[\mathrm{Re}(\mathrm{N}) \mathrm{Cl}_{2}\left(\right.\right.$ PPNPiPr $\left.\left.^{\mathrm{P}}\right)\right]$ is the dominant species in solution. Reduced steric shielding facilitates chloride coordination and thereby weakening of metal nitride bonding.

Heating of 6 with $\mathrm{PhC}(\mathrm{O}) \mathrm{Cl}$ (2 equiv.) at $80^{\circ} \mathrm{C}$ in 1,4dioxane over $15 \mathrm{~h}$ gives a new rhenium species (7) in $71 \%$ yield (Scheme 2). Paramagnetically shifted and sharp NMR signals support reduction to $\mathrm{Re}^{\mathrm{III}}$. Two chemically inequivalent $\mathrm{P}$-atoms $\left(\delta_{\mathrm{P}}=-1592.6,-1615.5 \mathrm{ppm} ;{ }^{2} \mathrm{JPP}_{\mathrm{PP}}=248 \mathrm{~Hz}\right)$ and the ${ }^{1} \mathrm{H}$ and ${ }^{13} \mathrm{C}$ NMR signatures are in agreement with pincer oxidation to an imine ligand. ${ }^{16}$ Formation of $\left[\mathrm{ReCl}_{3}\left(\mathrm{P}=\mathrm{NP}^{\mathrm{iP}}\right)\right] \quad\left(\mathrm{P}=\mathrm{NP}{ }^{\mathrm{iPr}}=\right.$ $\left.\mathrm{N}\left(\mathrm{CHCH}_{2} \mathrm{Pr}_{2}\right)\left(\mathrm{CH}_{2} \mathrm{CH}_{2} \mathrm{Pr}_{2}\right)\right)$ was confirmed by LIFDI-MS and comparison with an authentic sample. ${ }^{16}$ Crystallographic characterization (Figure 1d) evidences nitride transfer and pincer dehydrogenation. ${ }^{16}$ Two products account for $94 \%$ of the nitride ligand, i.e. benzamide (30\%), and benzonitrile (64\% with equimolar benzoic acid), respectively. $\mathrm{PhCN}$ and $\mathrm{PhCO}_{2} \mathrm{H}$ are products from the reaction of benzamide with benzoyl chloride,$^{23}$ supporting that $\mathrm{PhC}(\mathrm{O}) \mathrm{NH}_{2}$ is the immediate product of nitride benzoylation and $2 \mathrm{e}^{-} / 2 \mathrm{H}^{+}$-transfer from the pincer ligand. Related reactivity was observed for $\left[\mathrm{Ru}(\mathrm{N})\left(H_{\mathrm{PNP}}^{\mathrm{tBu}}\right)\right]^{+}$, which gives $\left[\mathrm{Ru}\left(\mathrm{NH}_{3}\right)\left(\mathrm{O}_{2} \mathrm{CPh}\right)\left(\mathrm{P}=\mathrm{NP}^{t \mathrm{Bu}}\right)\right]^{+}$upon reaction with para-methoxy benzoic acid. ${ }^{24}$ However, in that case azide was used as nitrogen source rather than $\mathrm{N}_{2}$.

Next, re-reduction of the imine pincer ligand was examined to evaluate the amine/imine redox couple as cooperating ligand reservoir for $2 \mathrm{e}^{-} / 2 \mathrm{H}^{+}$proton coupled electron transfer (PCET). 7 does not react with $\mathrm{H}_{2}$ under thermal or photolytic conditions. However, chemical reduction is possible with stepwise addition of $\mathrm{Li}\left[\mathrm{HBEt}_{3}\right]$ and diphenylammonium chloride (Scheme 2). On this route, 4 is obtained in $62 \%$ spectroscopic yield due to the formation of rhenium hydrides as byproducts, which reform 7 upon hydrolytic quenching.

We therefore turned to electrochemical regeneration of 4 . The CV of 7 exhibits quasi-reversible reduction at $-1.70 \mathrm{~V}$. Titrating in benzoic acid (0-15 eq.; Figure $3 a$ ) results in a pronounced increase of the cathodic current and buildup of a second, quasi-reversible reductive feature at $-1.84 \mathrm{~V}$, which is assigned to parent 4 . The strong increase of the first wave is indicative of multielectron reduction in the presence of acid. In fact, the viable intermediate $\left[\operatorname{ReCl}_{3}\left(\mathrm{PNP}^{\mathrm{PP}}\right)\right]$ (8) exhibits a quasireversible reduction at $-1.16 \mathrm{~V},{ }^{16}$ confirming a potential inversion after the first $\mathrm{e}^{-} / \mathrm{H}^{+}$-transfer to 7 . The electrochemical data in the presence of acid is therefore rationalized with two subsequent PCET steps at around $-1.7 \mathrm{~V}$ that regenerate 4.

Controlled potential electrolysis (CPE) of 7 at the half peak potential of the first reduction feature $(E=-1.65 \mathrm{~V})$ did not give appreciable amounts of 4 in the presence of benzoic acid (10 eq). 2,6-Dichlorophenol (DCP) was therefore employed, which exhibits about same $p K_{a}$ as benzoic acid $\left(p K_{a}{ }^{T H F}=25.1\right)^{25}$ yet a conjugate base that is less prone to metal coordination. In fact, 
This is the peer reviewed version of the following article: F. Schendzielorz et al., Angew. Chem. Int. Ed., 2019, 58, 83o-834, which has been published in final form at DOI: 10.1002/anie.201812125. This article may be used for non-commercial purposes in accordance with Wiley Terms and Conditions for Use of Self-Archived Versions.

bulk electrolysis of 7 at $E=-1.65 \mathrm{~V}$ in the presence of DCP $(10$ eq.) for $7 \mathrm{~h}$ results in full consumption of $\mathbf{7}$ and formation of $\mathbf{4}$ as the only electroactive species. ${ }^{1} \mathrm{H}$ NMR spectroscopy confirmed a yield of $99 \%$ and coulometry the transfer of $1.96 \mathrm{e}^{-}$per 7 .
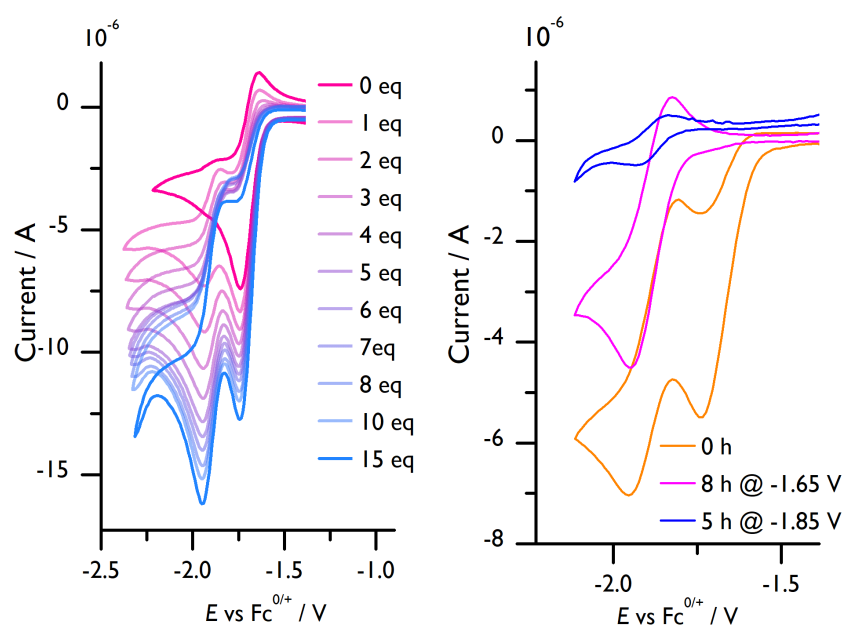

Figure 3. Left: CV of 7 in presence of $0-15$ eq. benzoic acid. Right: CV of 7 with 10 eq 2,6-dichlorophenol under $\mathrm{N}_{2}$ before CPE (orange), after $8 \mathrm{~h}$ CPE at -1.65 $\mathrm{V}$ (pink) and after subsequent $5 \mathrm{~h} \mathrm{CPE}$ at $-1.85 \mathrm{~V}$ (blue). becomes less favorable which can be overcome by photolysis with visible light. Based on the experimental and theoretical data, the photochemical reactivity is associated with the population of a dissociative state with $\mathrm{Re} \rightarrow \mathrm{N}_{2}$ MLCT character. The higher coordination number weakens nitride bonding, thus enabling the use of a weaker electrophile than alkyl triflates. Importantly, the cooperating pincer ligand serves as a reservoir for nitrogen hydrogenolysis upon $2 \mathrm{e}^{-} / 2 \mathrm{H}^{+}-\mathrm{PCET}$ and electrochemical rehydrogenation. Our results demonstrate how metal-ligand cooperativity and photo- and electrochemical approaches can facilitate the design of platforms for $\mathrm{N}_{2}$-fixation.

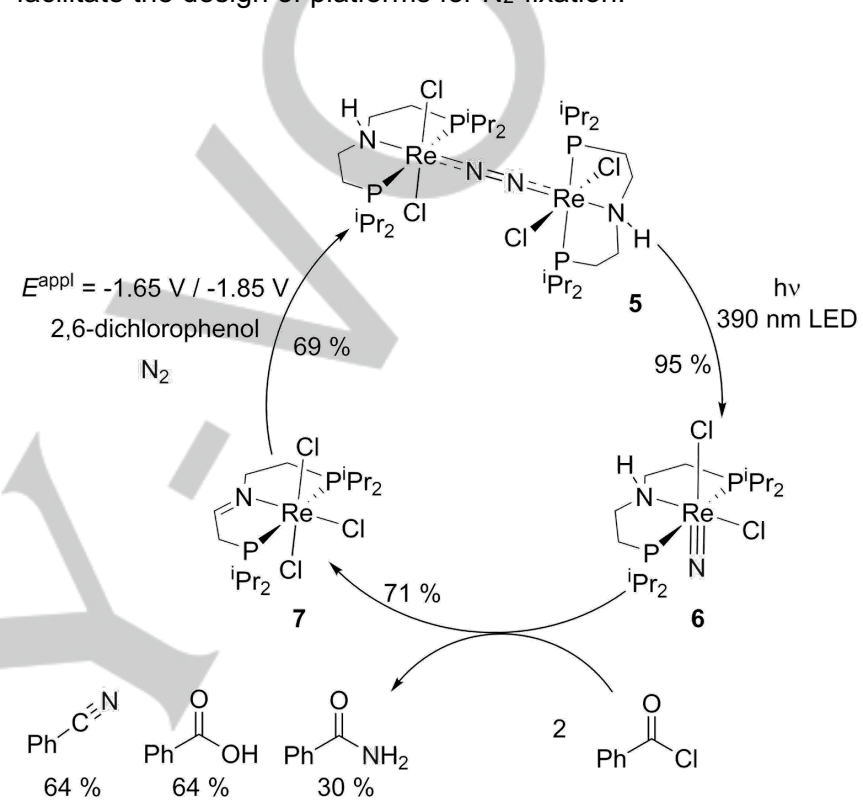

Scheme 3. Optimized, three-step synthetic cycle.

\section{Acknowledgements}

This work was supported by the European Research Council (ERC Consolidator Grant Agreement 646747, grant holder S.Sch.). V.K. acknowledges a $50^{\text {th }}$ Anniversary Prize Fellowship from the University of Bath and its Balena High Performance Computing (HPC) Service. The authors thank Dr. C. Volkmann for solving the crystal structure of complex 8.

Keywords: Nitrogen Fixation • Rhenium • Pincer Ligand • Photochemistry $\cdot$ Electrochemistry

J. Y. Becker, S. Avraham, B. Posin, J. Electroanal. Chem. Interfacial Electrochem. 1987, 230, 143. (d) N. P. Luneva, S. A. Mironova, A. E. Shilov, M. Y. Antipin, Y. T. Struchkov, Angew. Chem., Int. Ed. Engl. 1993, 32, 1178. (e) T. Munisamy, R. R. Schrock, Dalton Trans. 2012, 41, 130. (f) T. J. Del Castillo, N. B. Thompson, J. C. Peters, J. Am. Chem. Soc. 2016, 138, 5341. (g) M. J. Chalkley, T. J. Del Castillo, B. D. Matson, J. C. Peters, J. Am. Chem. Soc. 2018, 140, 6122.

[5] Y. Tanabe, Y. Nishibayashi, Coord. Chem Rev. 2013, 257, 2551.

[4] (a) C. J. Pickett, J. Talarmin, Nature 1985, 317, 652. (b) J. Y. Becker, B. Posin, J. Electroanal. Chem. Interfacial Electrochem. 1988, 250, 385. (c) 
This is the peer reviewed version of the following article: F. Schendzielorz et al., Angew. Chem. Int. Ed., 2019, 58, 830-834, which has been published in final form at DOI: 10.1002/anie.201812125. This article may be used for non-commercial purposes in accordance with Wiley Terms and Conditions for Use of Self-Archived Versions.

[6] (a) J. S. Figueroa, N. A. Piro, C. R. Clough, C. C. Cummins, J. Am. Chem. Soc. 2006, 128, 940. (b) J. J. Curley, E. L. Sceats, C. C. Cummins, J. Am. Chem. Soc. 2006, 128, 14036.

[7] (a) I.Klopsch, M. Kinauer, M. Finger, C. Würtele, S. Schneider, Angew. Chem. Int. Ed. 2016, 55, 4786. (b) I. Klopsch, F. Schendzielorz, C Volkmann, C. Würtele, S. Schneider, Z. Anorg. Allg. Chem. 2018, 644, 916.

[8] M. M. Guru, T. Shima, Z. Hou, Angew. Chem. Int. Ed. 2016, 128, 12504.

[9] A. J. Keane, W. S. Farrell, B. L. Yonke, P. Y. Zavalij, L. R. Sita, Angew. Chem. Int. Ed. 2015, 54, 10220.

[10] Q. Liao, A. Cavaillé, N. Saffon-Merceron, N. Mézailles, Angew. Chem. Int. Ed. 2016, 128, 11378.

[11] L. M. Duman, L. R. Sita, J. Am. Chem. Soc. 2017, 139, 17241.

[12] M. F. Espada, S. Bennaamane, Q. Liao, N. Saffon-Merceron, S. Massou, E. Clot, N. Nebra, M. Fustier-Boutignon, N. Mézailles, Angew. Chem. Int. Ed. 2018, 130, 13047.

[13] (a) I. Klopsch, M. Finger, C. Würtele, B. Milde, D. B. Werz, S. Schneider, J. Am. Chem. Soc. 2014, 136, 6881. (b) B. M. Lindley, R. S. van Alten, M. Finger, F. Schendzielorz, C. Würtele, A. J. M. Miller, I. Siewert, S. Schneider, J. Am. Chem. Soc. 2018, 140, 7922.

[14] G. Silantyev, M. Förster, B. Schluschaß, J. Abbenseth, C. Würtele, C. Volkmann, M.C. Holthausen, S. Schneider, Angew. Chem. Int. Ed. 2017, $56,5872$.

[15] I. Klopsch, E.Y. Yuzik-Klimova, S. Schneider, Top. Organomet. Chem. 2017, 60, 71.

[16] For synthetic, spectroscopic, computational and crystallographic details see Electronic Supporting Information (ESI).
[17] (a) J. Chatt, G. J. Leigh, D. M. P. Mingos, J. Chem. Soc. (A) 1969, 1674 (b) J. Abbenseth, M. Diefenbach, S. C. Bete, C. Würtele, C. Volkmann, S. Demeshko, M. C. Holthausen, S. Schneider, Chem. Commun. 2017, $53,5511$.

[18] All electrochemical data is reported vs. $\mathrm{FeCp}_{2}+/ \mathrm{FeCp}_{2}$.

[19] C. E. Laplaza, M. J. A. Johnson, J. C. Peters, A. L. Odom, E. Kim, C. C. Cummins, G. N. George, I. J. Pickering, J. Am. Chem. Soc. 1996, 118, 8623.

[20] C. E. Laplaza, C. C. Cummins, Science 1995, 268, 861.

[21] V. Krewald, Dalton Trans. 2018, 47, 10320.

[22] (a) J. J. Curley, T. R. Cook, S. Y. Reece, P. Müller, C. C. Cummins, J. Am. Chem. Soc. 2008, 130, 9394. (b) H. Kunkely, A. Vogler, Angew. Chem. Int. Ed. 2010, 49, 1591. (c) A. S. Huss, J. J. Curley, C. C Cummins, D. A. Blank, J. Phys. Chem. B 2013, 117, 1429. (d) T. Miyazaki, H. Tanaka, Y. Tanabe, M. Yuki, K. Nakajima, K. Yoshizawa, Y. Nishibayashi, Angew. Chem. Int. Ed. 2014, 53, 11488. (e) L. M. Duman, W. S. Farrell, P. Y. Zavalij, L. R. Sita, J. Am. Chem. Soc. 2016, 138, 14856.

[23] D. Davidson, H. Skovronek, J. Am. Chem. Soc. 1958, 80, 376.

[24] (a) B. Askevold, J. Torres Nieto, S. Tussupbayev, M. Diefenbach, E. Herdtweck, M. C. Holthausen, S. Schneider, Nature. Chem. 2011, 3, 532. (b) B. M. Lindley, Q. J. Bruch, P. S. White, F. Hasanayn, A. J. M. Miller, J. Am. Chem. Soc. 2017, 139, 5305.

[25] a) D. Barrón, J. Barbosa, Anal. Chim. Acta 2000, 403, 339. b) D. Barrón, J. Barbosa, Anal. Chim. Acta 1992, 265, 157. 
This is the peer reviewed version of the following article: F. Schendzielorz et al., Angew. Chem. Int. Ed., 2019, 58, 830-834, which has been published in final form at DOI: 10.1002/anie.201812125. This article may be used for non-commercial purposes in accordance with Wiley Terms and Conditions for Use of Self-Archived Versions.

\section{Entry for the Table of Contents}

\section{COMMUNICATION}

Cooperative Fixation: $\mathrm{N}_{2}$ fixation to benzonitrile and benzamide is reported within a three-step cycle that utilizes electrochemical reduction, photochemical $\mathrm{N}_{2}$ splitting and thermal $\mathrm{N}$-transfer with benzoylchloride. Product formation is enabled by cooperativity of the functional pincer ligand, which serves as a $2 \mathrm{H}^{+} / 2 \mathrm{e}^{-}$ reservoir.

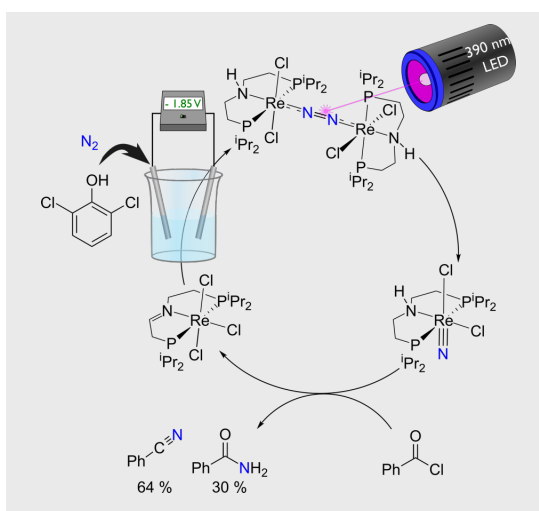

F. Schendzielorz, M. Finger, J. Abbenseth, C. Würtele, V. Krewald, ${ }^{*}$ S. Schneider ${ }^{*}$

Page No. - Page No.

Metal-Ligand Cooperative Synthesis of Benzonitrile via Electrochemical Reduction and Photolytic Splitting of Dinitrogen 